\title{
Supplementary Informations
}

Redox-active biomolecular architectures and self-assembled monolayers based on a cyclodecapeptide regioselectively addressable functional template

Charles H. Devillers ${ }^{\dagger \S}$, Didier Boturyn ${ }^{\S}$, Christophe Bucher ${ }^{r^{* *}}$, Pascal Dumy $y^{\S *}$, Pierre Labbét, Jean-Claude Moutet ${ }^{\dagger}$, Guy Royal ${ }^{\dagger}$,Eric Saint-Aman ${ }^{\dagger}$.

${ }^{\dagger}$ Laboratoire d'Electrochimie Organique et de Photochimie Rédox, UMR CNRS 5630, Institut de Chimie Moléculaire de Grenoble, FR CNRS 2607, Université Joseph Fourier, BP 53, 38041 Grenoble Cédex 9, France

${ }^{\S}$ Laboratoire d'Etudes Dynamiques et Structurales de la Sélectivité, UMR CNRS 5616, Institut de Chimie Moléculaire de Grenoble, FR CNRS 2607, Université Joseph Fourier Grenoble 1, BP 53, 38041 Grenoble Cédex 9, France

Détails on the multi-step synthesis of 2 p 2

HPLC profile and MS analysis of $\mathbf{1}$ p.3-4

HPLC profile and MS analysis of 2 p.5-7

HPLC profile and MS analysis of $\mathbf{6}$ p.8-9

HPLC profile and MS analysis of $\mathbf{1 0}$ p.10-11

HPLC profile and MS analysis of $\mathbf{1 1}$ p.12-13

HPLC profile and MS analysis of $\mathbf{1 2}$ p.14-15

HPLC profile and MS analysis of $\mathbf{1 3}$ p.16-17

Ellipsometric measurements on SAM of 2 p.18 
Details on the multi-step synthesis of 2.
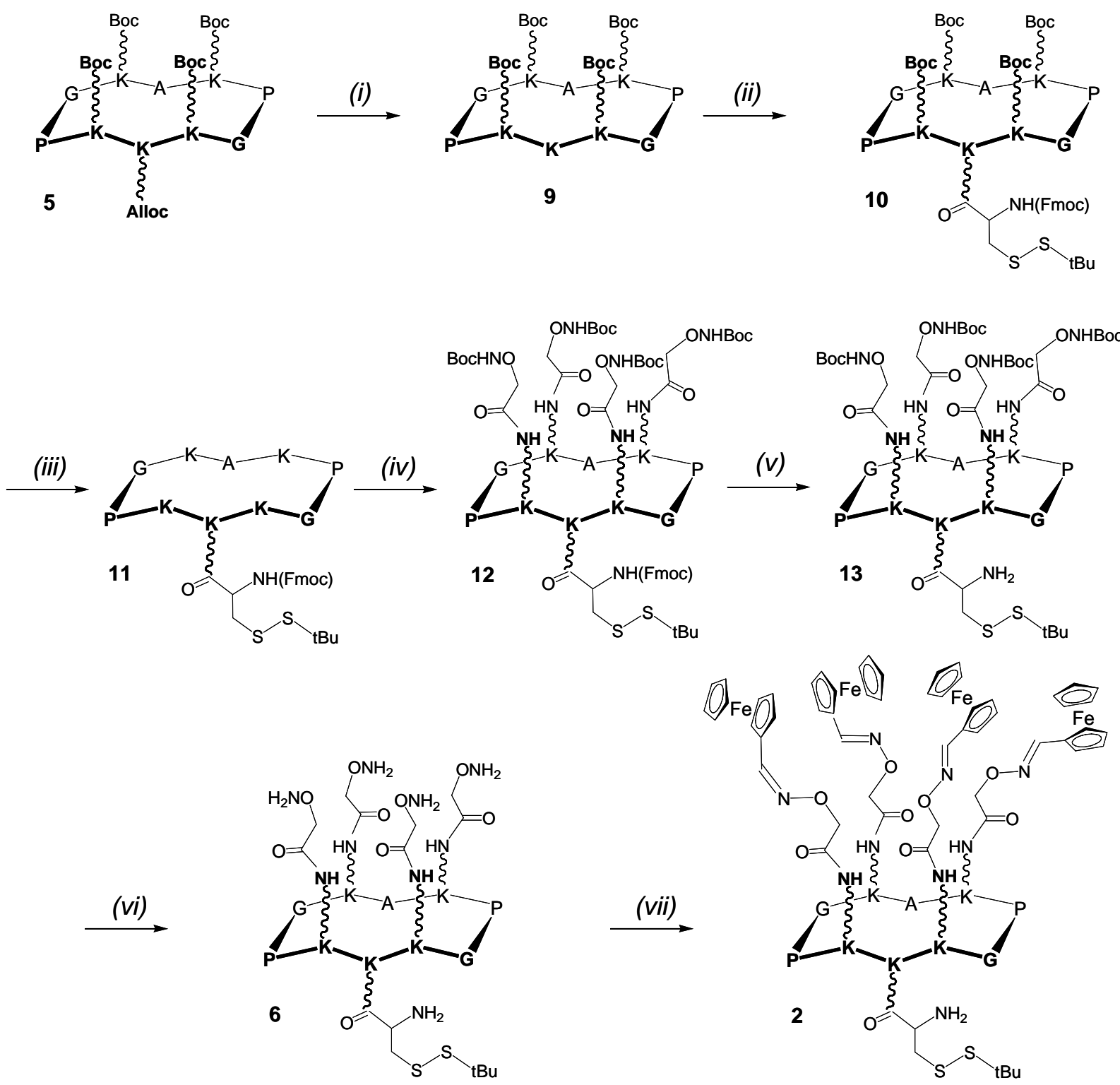

(i) $\mathrm{Pd}\left(\mathrm{PPh}_{3}\right)_{4}, \mathrm{PhSiH}_{3}, \mathrm{CH}_{2} \mathrm{Cl}_{2}, 1 \mathrm{~h}$

(ii) FmocCys(S-t-Bu)OH, PyBOP, DIPEA, DMF, $1 \mathrm{~h}$

(iii) $\mathrm{TFA} / \mathrm{CH}_{2} \mathrm{Cl}_{2}(50 / 50)(\mathrm{v} / \mathrm{V}), 1 \mathrm{~h}$

(iv) BocNHOCH${ }_{2} \mathrm{CO}-\mathrm{NHS}$, DIPEA, DMF, $1 \mathrm{~h}$

(v) DMF/piperidine $(80 / 20)(\mathrm{v} / \mathrm{v}), 30 \mathrm{~min}$

(vi) $\mathrm{TFA} / \mathrm{CH}_{2} \mathrm{Cl}_{2} / \mathrm{TIS} / \mathrm{H}_{2} \mathrm{O}(50 / 40 / 5 / 5)(\mathrm{v} / \mathrm{v}), 1 \mathrm{~h}$

(vii) $\mathrm{Fc}-\mathrm{CHO}$, acetate buffer $\left(0.1 \mathrm{~mol} \mathrm{~L}^{-1}, \mathrm{pH}=4.6\right) / \mathrm{CH}_{3} \mathrm{CN}(50 / 50)(\mathrm{v} / \mathrm{v}), 7 \mathrm{~h}$ 


\begin{tabular}{|c|c|c|c|}
\hline \multicolumn{2}{|r|}{ SAMPLE } & \multicolumn{2}{|c|}{ INFORMATION } \\
\hline Sample Name: & (1) & Acquired By: & labo \\
\hline Samole Type: & Unknown & Date Acquired: & $17 / 03 / 2004$ 08:52-23 \\
\hline Vial: & 1 & Acq. Method Set: & 214 250 \\
\hline njection \#: & 1 & Date Pocessed: & $17 / 03 / 2004$ 10:29:14, $17 / 03 / 2004$ \\
\hline Injection Volume: & $4.00 \mathrm{ul}$ & Pocessing Method: & $214 \mathrm{~nm}, 250 \mathrm{~nm}$ \\
\hline $\begin{array}{l}\text { Run Tme: } \\
\text { Sample Set Name: }\end{array}$ & 18.0 Minutes & $\begin{array}{l}\text { Channel Name: } \\
\text { Proc. Chnil. Descr.: }\end{array}$ & $\begin{array}{l}\text { Satin Ch 1, Satin Ch } 2 \\
214 \mathrm{~nm} \text { 250-700nm }\end{array}$ \\
\hline
\end{tabular}
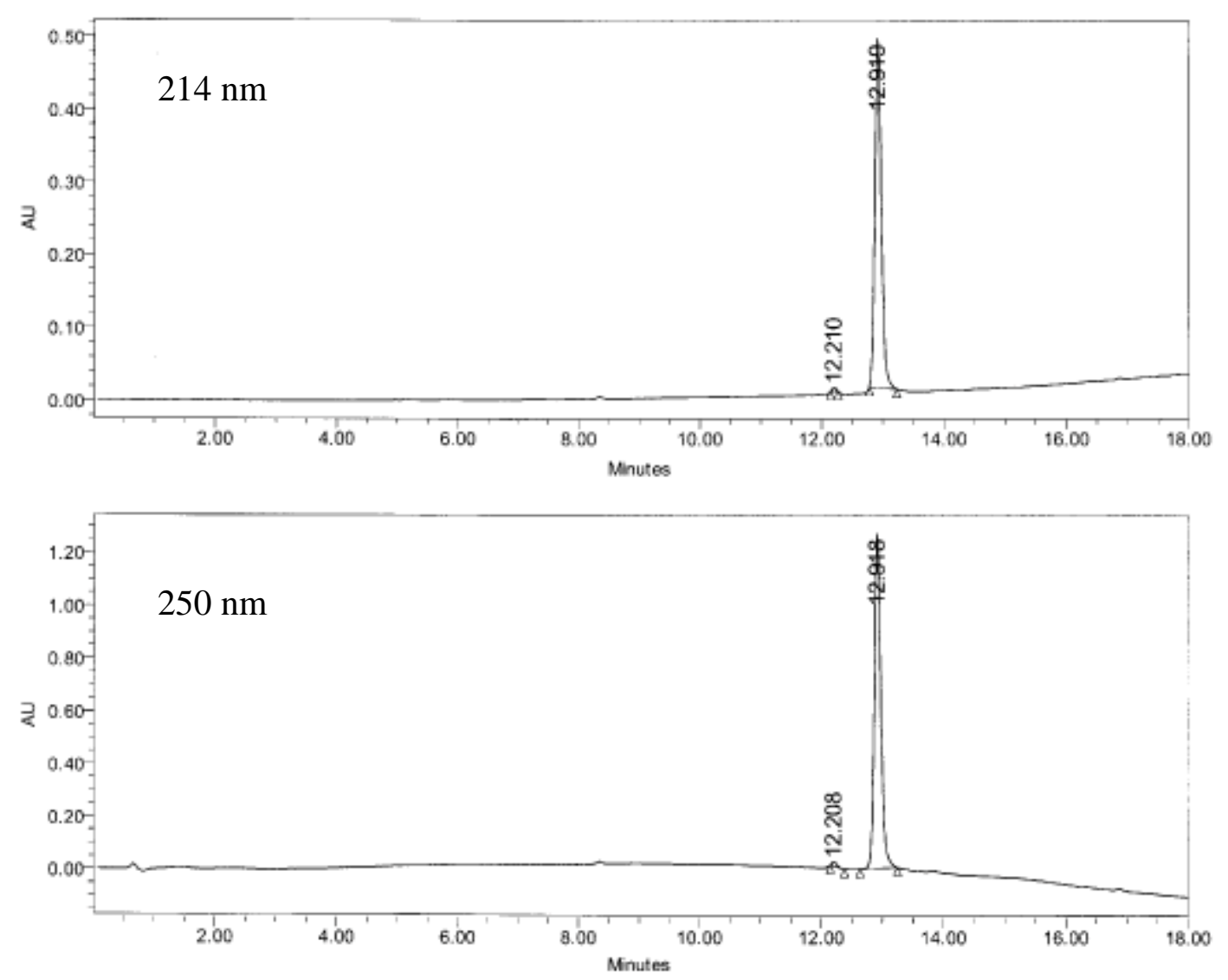

\begin{tabular}{|c|c|c|c|c|c|c|c|c|c|}
\hline & RT & Area & $\%$ Area & Height & & $\mathrm{RT}$ & Area & $\%$ Area & Height \\
\hline 1 & 12.208 & 86205 & 0.91 & 16675 & 2 & 12.210 & 21864 & 0.62 & 5167 \\
\hline
\end{tabular}




\section{Mass Spectrum Deconvolution Report}

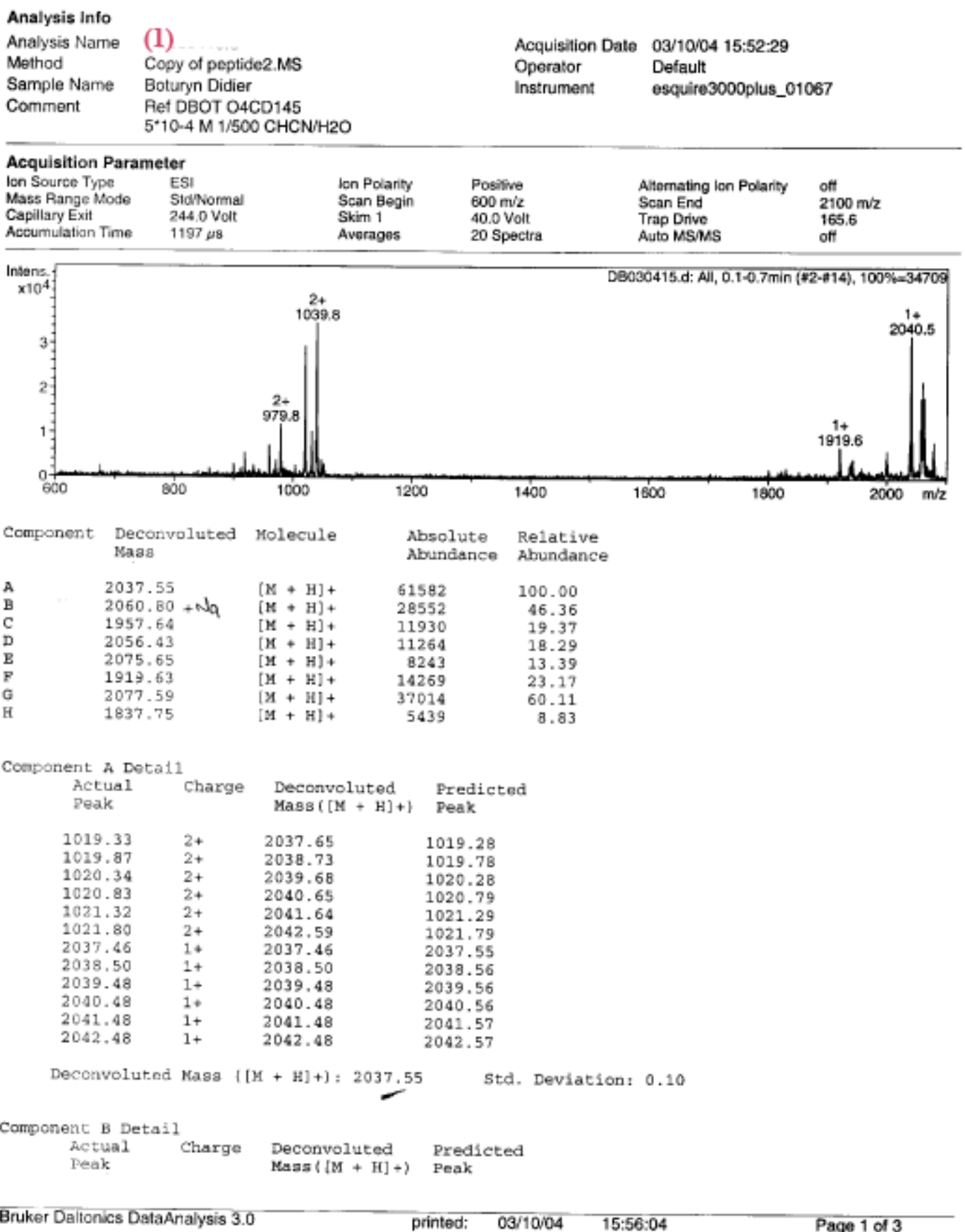




\section{Empower}

\section{Result Set Report}

Reported by User: labo

Project Name: Peptides

\begin{tabular}{|c|c|c|c|}
\hline \multicolumn{2}{|r|}{ SAMPLE } & \multicolumn{2}{|c|}{ INFORMATION } \\
\hline Sample Name: & (2) & Acquired By: & labo \\
\hline Samole Type: & Unknow $n$ & Date Acquired: & $20 / 02 / 20041553: 13$ \\
\hline Vial: & 1 & Acq. Method Set: & $214 \_250$ \\
\hline Injection \#: & 12 & Date Processed: & $20 / 02 / 2004$ 14:11:13 \\
\hline Injection Volume: & $4.00 \mathrm{ul}$ & Processing Method: & 214nm, 250n.า \\
\hline Run Time: & 18.0 Mnutes & Channel Narne: & Satin Ch $1, S \sin$ Ch 2 \\
\hline Sample Set Name: & & Proc. Onnl. Descr.: & $214 \mathrm{~nm}, 250-700 \mathrm{~nm}$ \\
\hline
\end{tabular}
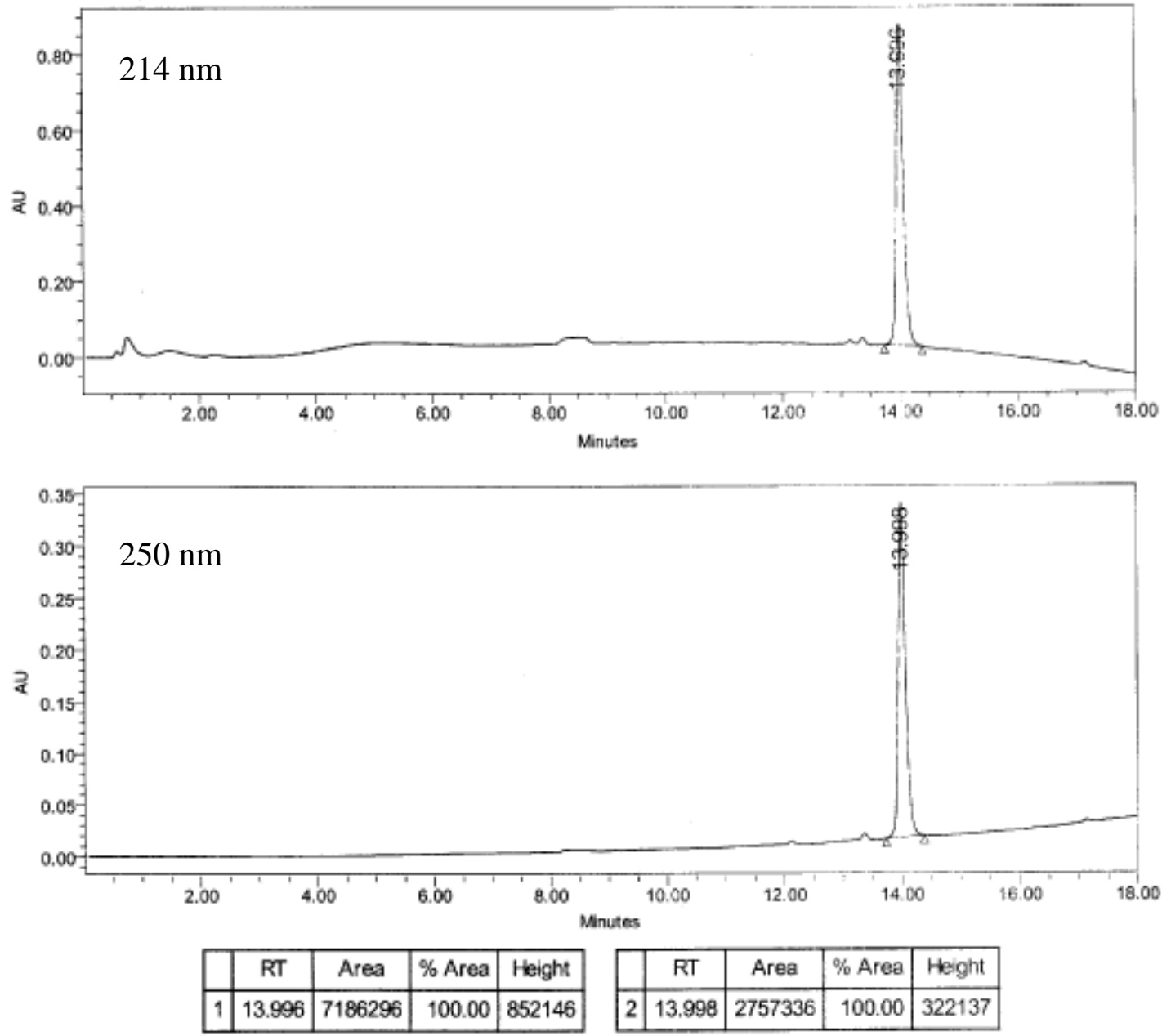


\section{Display Report}

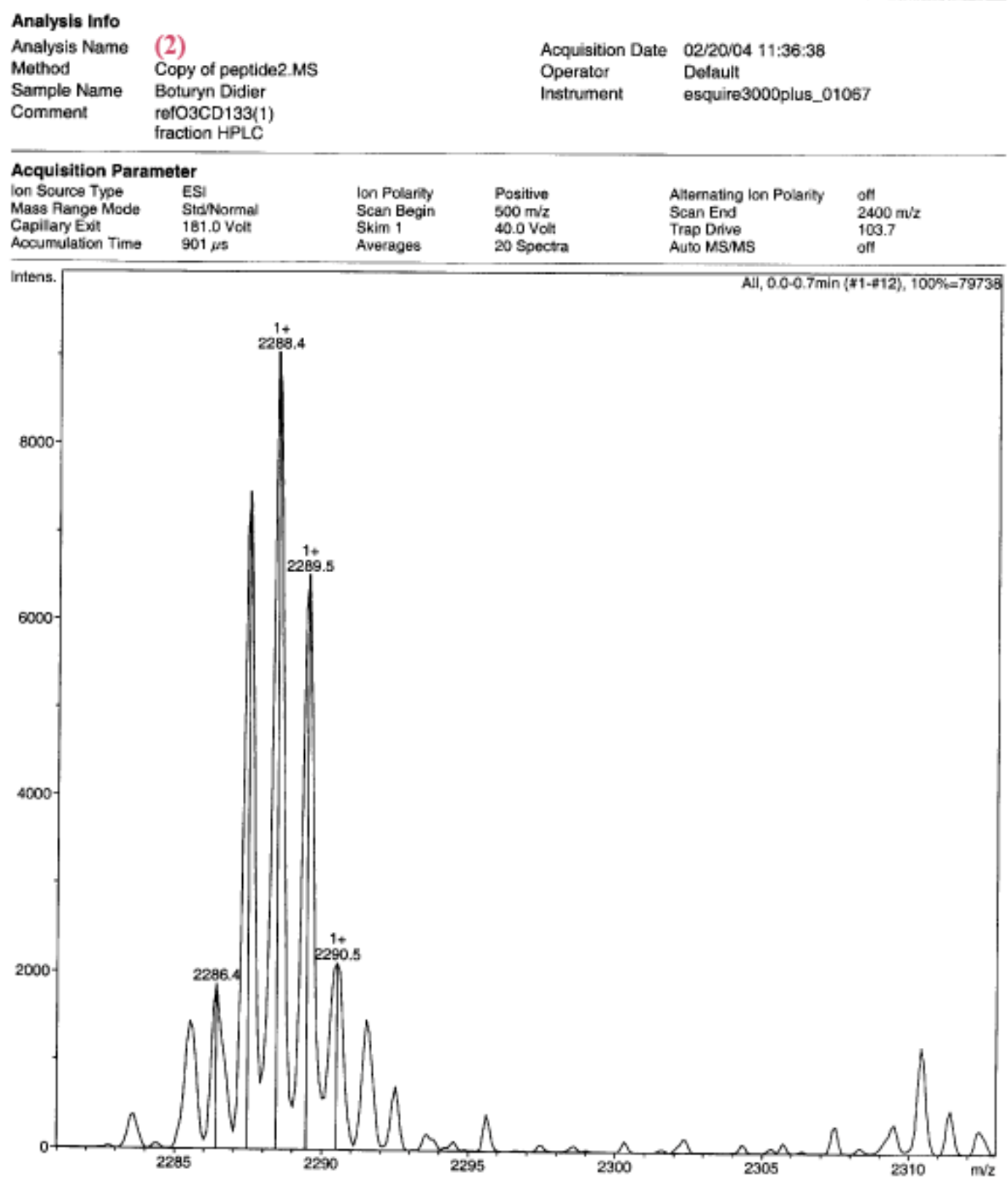

Bruker Daltonics DataAnalysis 3.0 


\section{Mass Spectrum Deconvolution Report}

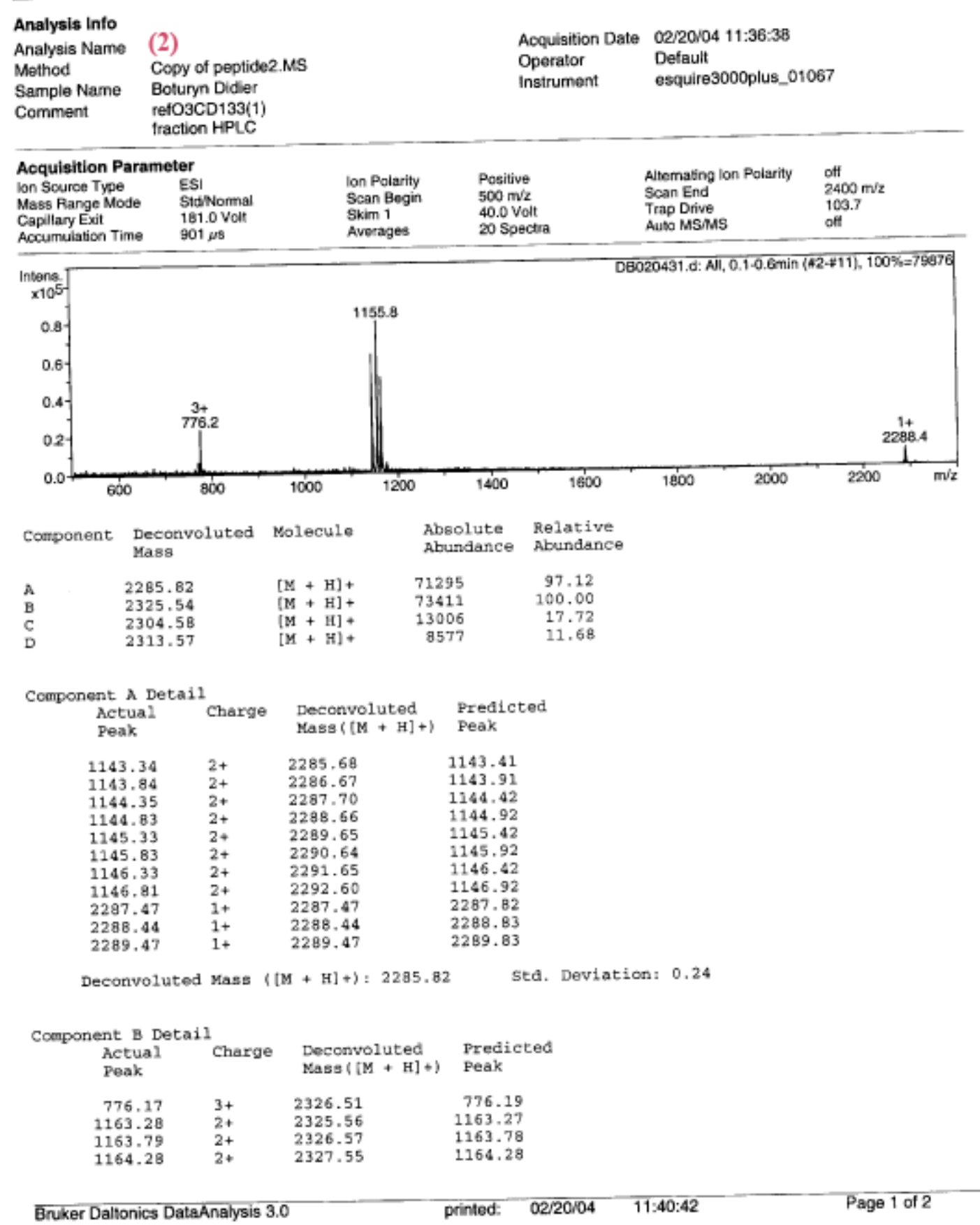




\section{Empower}

Result Set Report

Reported by User: labo

Project Name: Peptides

\begin{tabular}{|c|c|c|c|}
\hline \multicolumn{2}{|r|}{ SAMPLE } & \multicolumn{2}{|c|}{ INFORMATION } \\
\hline Sarrple Name: & (6) & Acquired By: & labo \\
\hline Sample Type: & Unknown & Date Acquired: & $10 / 02 / 2004$ 16:14:51 \\
\hline Vial: & 1 & Acq. Method Set: & 214_250 \\
\hline $\begin{array}{l}\text { Injection \#: } \\
\text { hjection Volume: }\end{array}$ & $\begin{array}{l}15 \\
20.00 \mathrm{ul}\end{array}$ & $\begin{array}{l}\text { Date Processed: } \\
\text { Pocessing Method: }\end{array}$ & $\begin{array}{l}10 / 02 / 200416: 32: 51 \\
214 \mathrm{~nm} .250 \mathrm{~nm}\end{array}$ \\
\hline $\begin{array}{l}\text { Run Time: } \\
\text { Sample Set Name: }\end{array}$ & 18.0 Mnutes & $\begin{array}{l}\text { Channel Name: } \\
\text { Proc. Chnl. Descr.: }\end{array}$ & $\begin{array}{l}\text { Satin Ch 1, Satin Ch } 2 \\
214 \mathrm{~nm}, 250-700 \mathrm{~nm}\end{array}$ \\
\hline
\end{tabular}
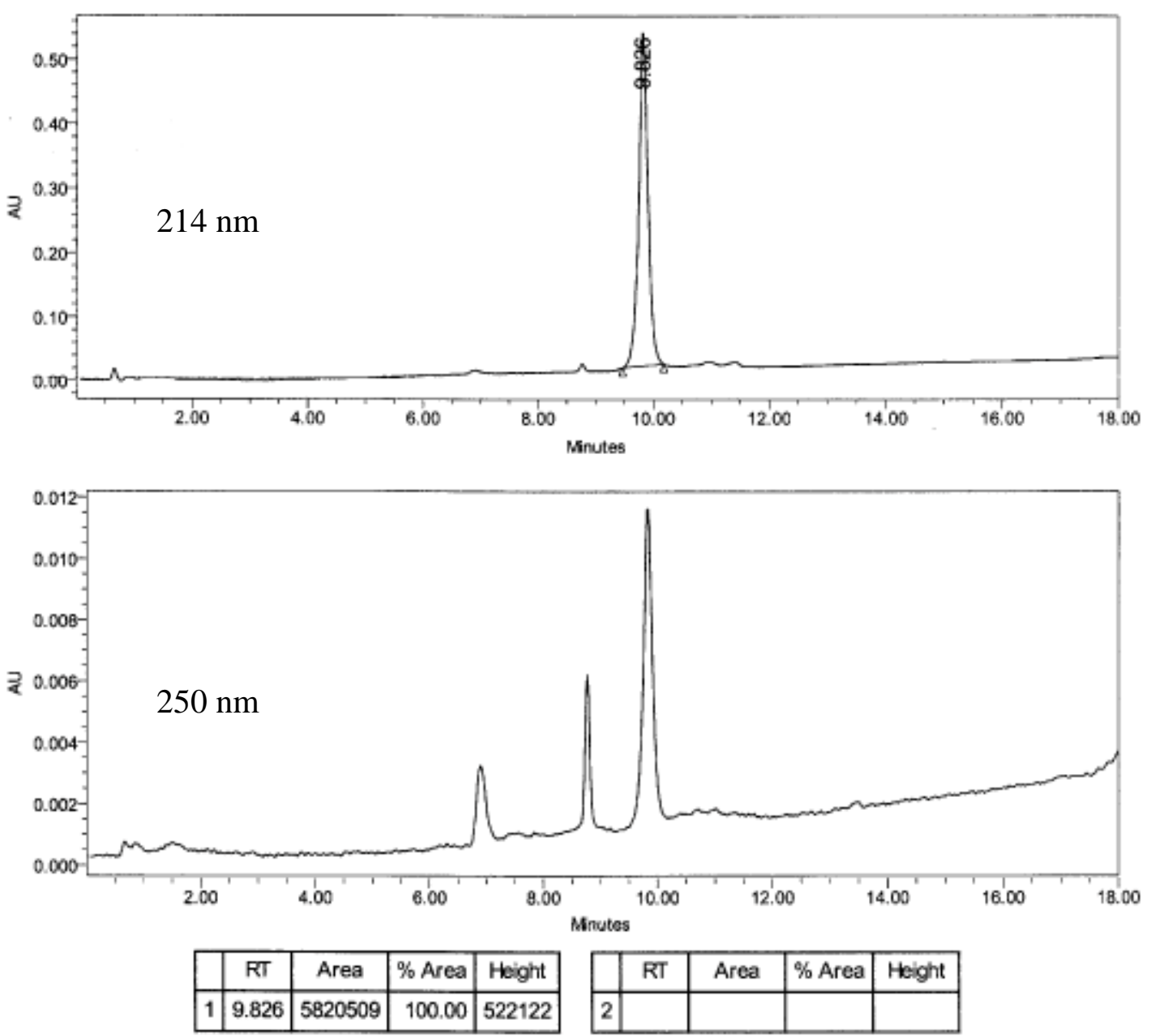

Report Method: Result Set Report

Printed 09:10:45

$12 / 02 / 2004$

Page: 2 of 2 


\section{Mass Spectrum Deconvolution Report}

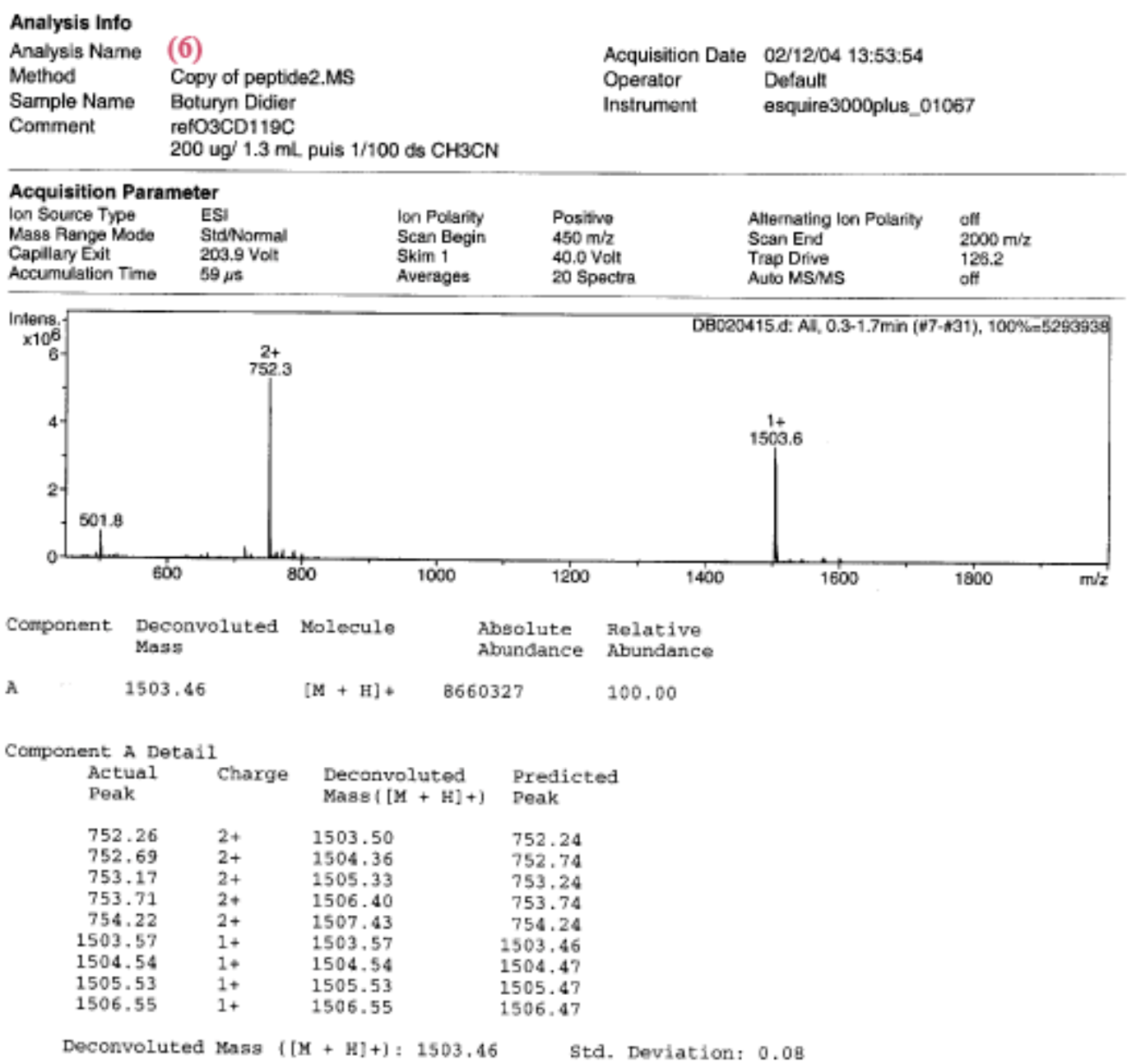




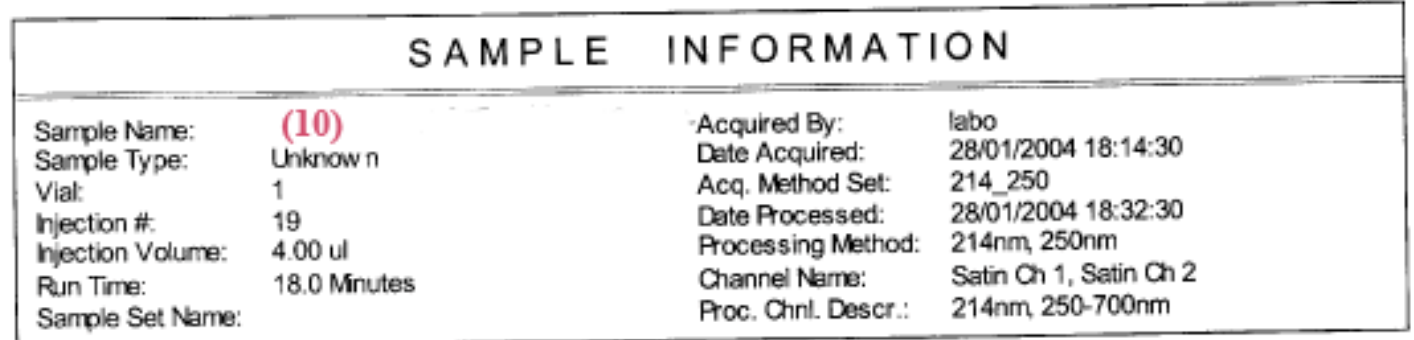
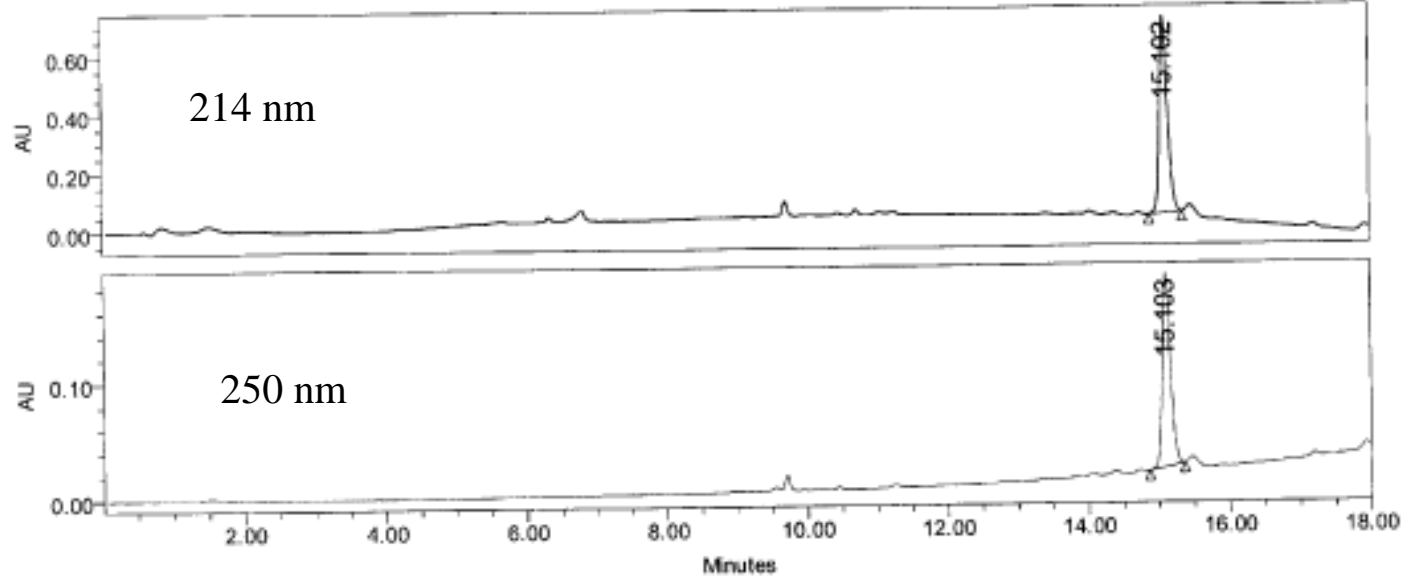

Orannel Satin Ch 1; Processed Channel: 214nm Result ld: 24956; Processing Method: 214nm Channel Satin Ch 2; Processed Channel: 250-700nm; Result id: 24957; Processing Method: 250nm

Processed Channel Descr.: 214nm

\begin{tabular}{|l|l|c|c|c|c|}
\hline & $\begin{array}{c}\text { Processed } \\
\text { Channel Descr. }\end{array}$ & RT & Area & $\%$ Area & Height \\
\hline 1 & $214 \mathrm{~nm}$ & 15.102 & 5288830 & 100.00 & 673889 \\
\hline
\end{tabular}

Processed Channel Descr.: 250-700nm

\begin{tabular}{|c|c|c|c|c|c|}
\hline & $\begin{array}{c}\text { Processed } \\
\text { Channel Descr. }\end{array}$ & RT & Area & $\%$ Area & Height \\
\hline 1 & $250-700 \mathrm{~nm}$ & 15.103 & 1312933 & 100.00 & 165088 \\
\hline
\end{tabular}




\section{Mass Spectrum Deconvolution Report}

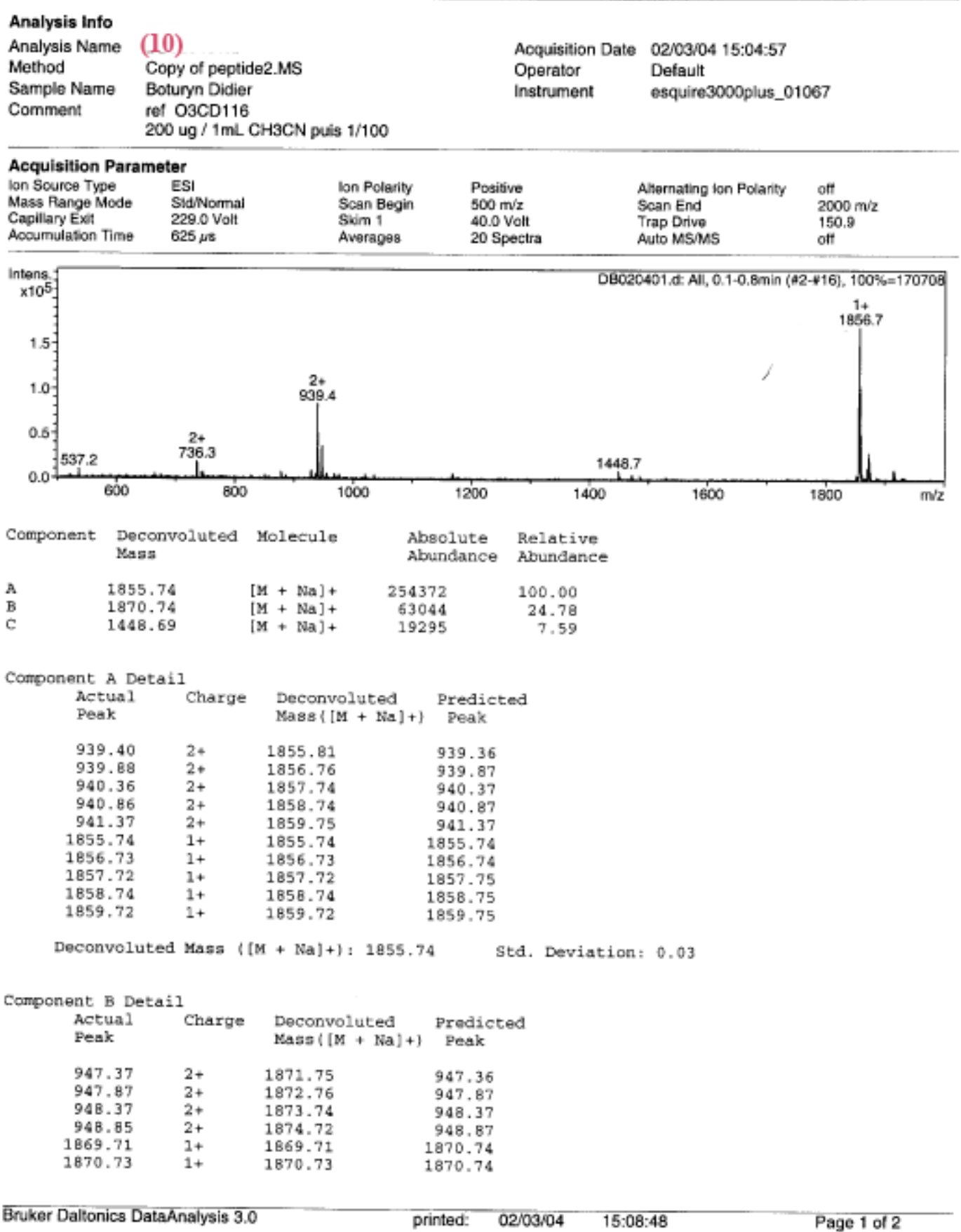




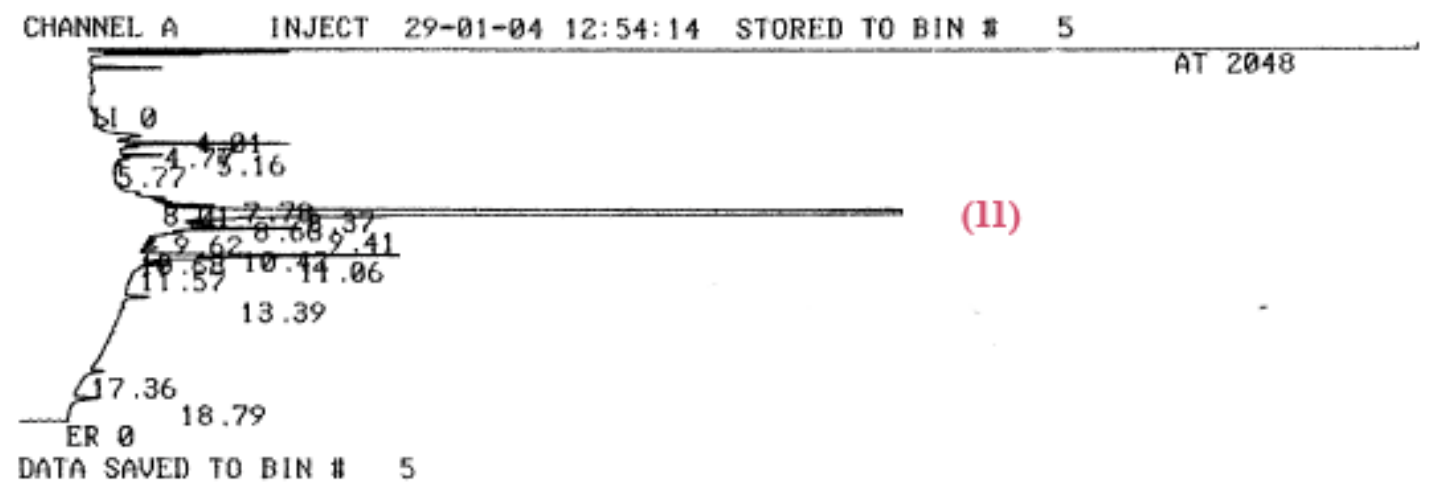

INPUT OUERRANGE AT RT $=\quad 8.87$

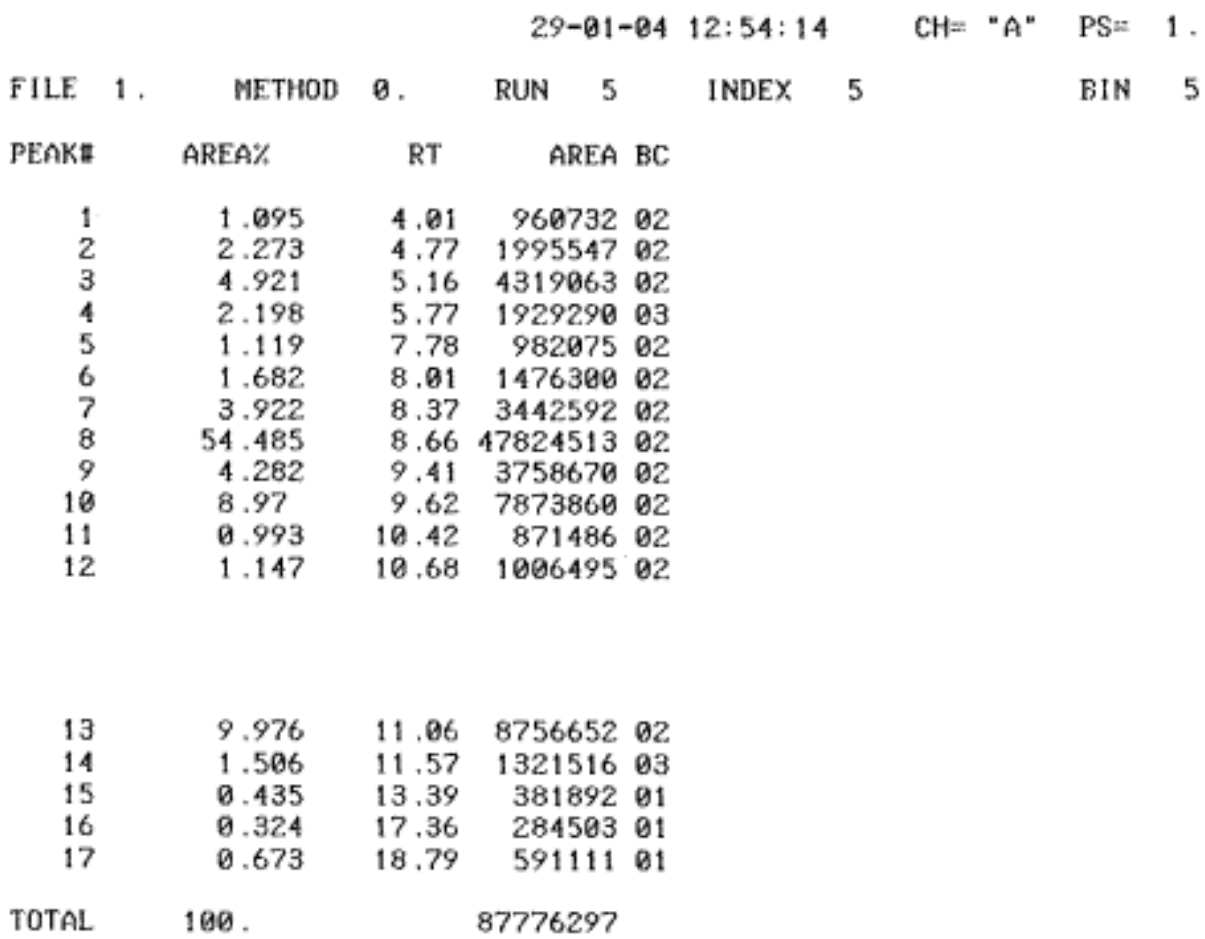




\section{Mass Spectrum Deconvolution Report}

\section{Analysis Info}

Analysis Name

Mothod

Sample Name

Comment
(11)

Copy of peptide2.MS

Boturyn Didier

ref O3CD 117

$100 \mathrm{ug} / 1 \mathrm{~mL} \mathrm{CH} 3 \mathrm{CN}$ puis $1 / 100$
Acquisition Date 02/03/04 15:30:53

Operator Delault

Instrument esquire3000plus_01067

\begin{tabular}{llllll} 
Acquisition Parameter & & & & \\
Ion Source Type & ESI & Ion Polarity & Posivive & Allernating lon Polarity & off \\
Mass Range Mode & StdiNormal & Scan Begin & $500 \mathrm{~m} / \mathrm{z}$ & Scan End & $1600 \mathrm{~m} / \mathrm{z}$ \\
Capdlary Exit & 199.0 Volt & Skim 1 & 40.0 Volt & Trap Drive & 121.4 \\
Accumulation Time & $197 \mu \mathrm{s}$ & Averages & 20 Spectra & Auto MSMS & aff \\
\hline
\end{tabular}

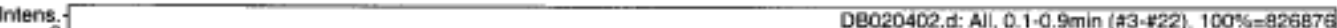

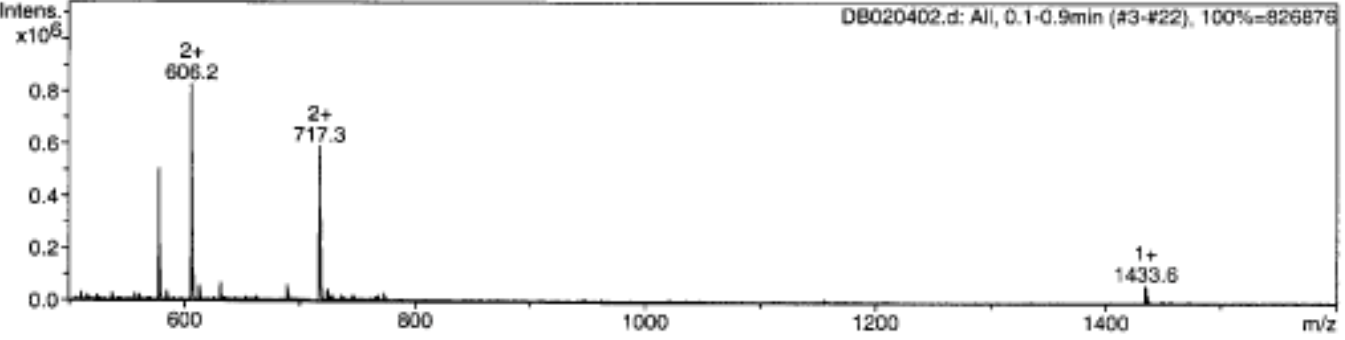

Component Deconvoluted Molecule Absolute Relative

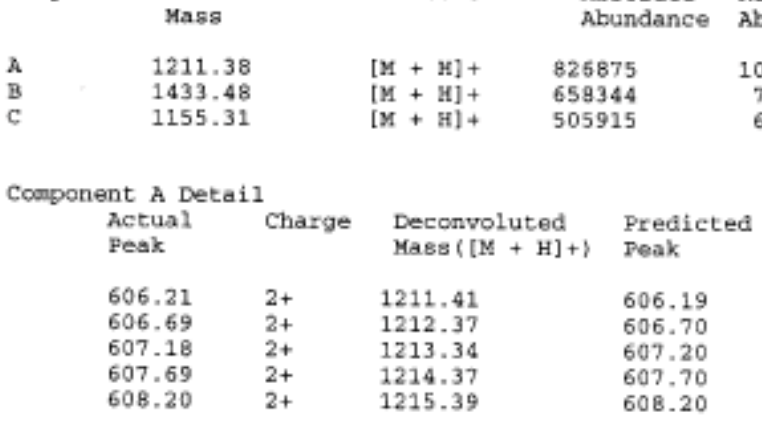

Deconvoluted Mass $([M+H]+)=1211.39 \quad$ Std. Deviation: 0.03

$\begin{array}{clll}\begin{array}{c}\text { Component B Detail } \\ \text { Actual } \\ \text { Peak }\end{array} & \text { Charge } & \begin{array}{l}\text { Deconvoluted } \\ \text { Mass }[[\mathrm{M}+\mathrm{H}]+)\end{array} & \begin{array}{l}\text { Predict } \\ \text { Peak }\end{array} \\ 713.25 & 2+ & 1433.49 & 717.24 \\ 717.73 & 2+ & 1434.45 & 717.74 \\ 718.23 & 2+ & 1435.46 & 718.25 \\ 718.74 & 2+ & 1436.46 & 718.75 \\ 719.23 & 2+ & 1437.46 & 719.25 \\ 1433.63 & 1+ & 1433.63 & 1433.48 \\ 1434.65 & 1+ & 1434.65 & 1434.48\end{array}$

Deconvoluted Mass $([\boldsymbol{K}+\mathrm{H}]+): 1433.48 \quad$ Std. Deviation: 0.09 


\section{Empower}

Result Set Report

Reported by User: labo

Project Name: Peptides

\begin{tabular}{|llll|}
\hline & & S A M P L E & IN F O R M A T I O N \\
\hline Sample Name: & $(12)$ & Acquired By: & labo \\
Sample Type: & Unknown & Date Acquired: & $30101 / 2004$ 16:02:04 \\
Vial: & 1 & Acq. Method Set: & 214 250 \\
njection \#: & 14 & Date Pocessed: & $30101 / 200416: 20: 04$ \\
hjection Volume: & 4.00 ul & Pocessing Method: & $214 \mathrm{~nm}, 250 \mathrm{~nm}$ \\
Run Time: & 18.0 Mnutes & Channel Name: & Satin Ch 1, Satin Ch 2 \\
Sample Set Name: & & Poc. Chnl. Descr.: & $214 \mathrm{~nm}, 250-700 \mathrm{~nm}$ \\
\hline
\end{tabular}
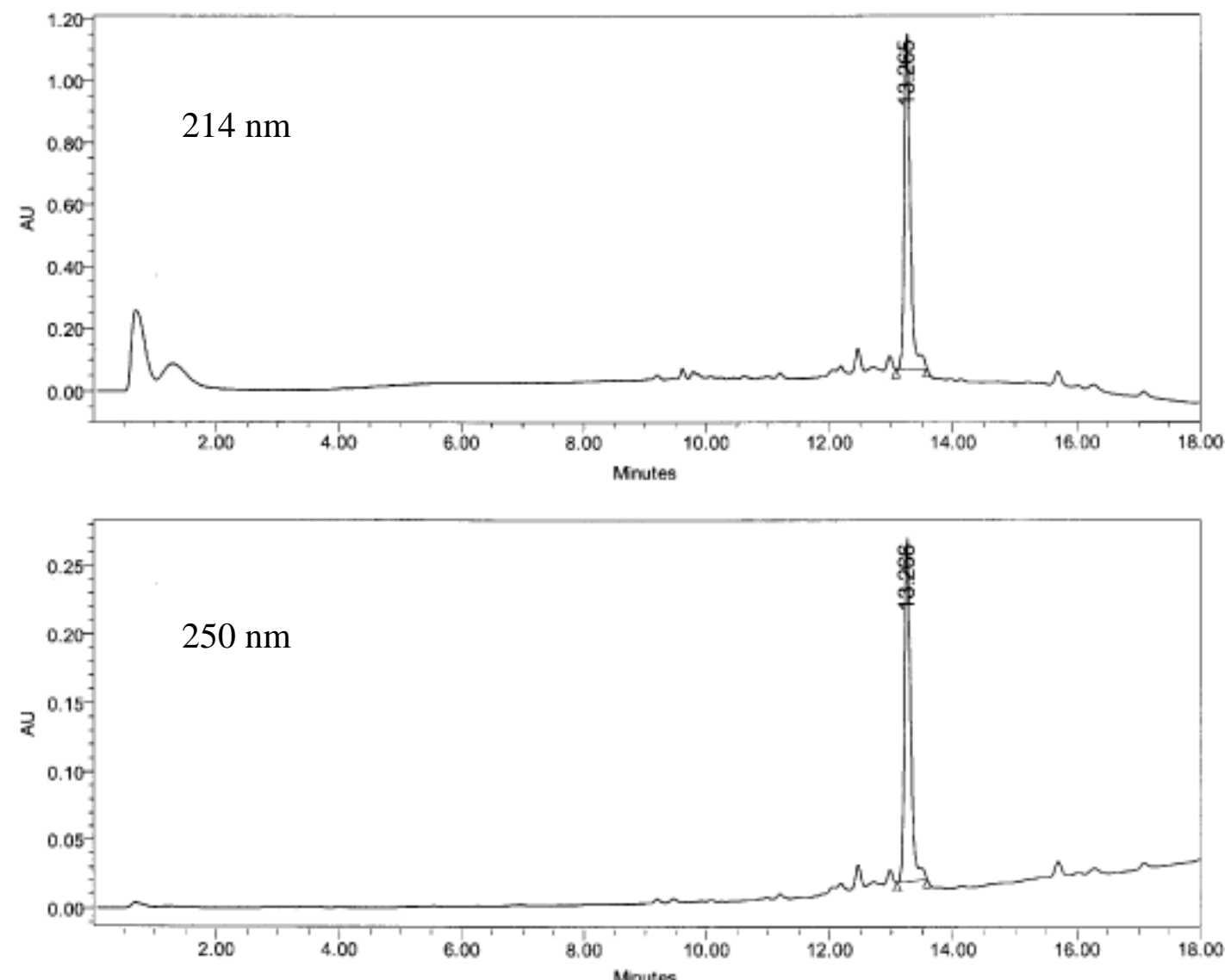

\begin{tabular}{|c|c|c|c|c|c|c|c|c|c|}
\hline & RT & Area & $\%$ Area & Height & & RT & Area & $\%$ Area & Height \\
\hline 1 & 13.265 & 7297156 & 100.00 & 1075519 & 2 & 13.266 & 1712388 & 100.00 & 248666 \\
\hline
\end{tabular}

Report Method: Result Set Report

Printed 16:27:18

$30 / 01 / 2004$

Page: 2 of 2 


\section{Display Report}

Analysis Info

Analysis Name

Method

Sample Name

Comment
(12)

Copy of peptide2.MS

Boturyn Didier

ref O3CD117日

100 ug $/ 0.5 \mathrm{~mL}$ CH3CN puis $1 / 100$
Acquisition Date 02/03/04 16:01:34

Operator Default

Instrument esquire3000plus_01067

Acquisition Parameter

lan Scurco Type ES

Mass Range Mode

ES!

Acoumulation Time

Stch/Norma

$253.4 \mathrm{Vor}$

Ion Polarity

Scan Begi

Positive

$800 \mathrm{~m} / z$

40.0 Volt
20 Spectra

Alternating Ion Polarity

Scan End

Trap Drive

Auto MSMS

off

Average

intens

$x 10^{5}$

2.5

.5

2.0

2.0

All, $0.1-0.3 \min (* 2-46), 100 \%=246835$

163.8

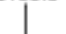

$$
2+
$$

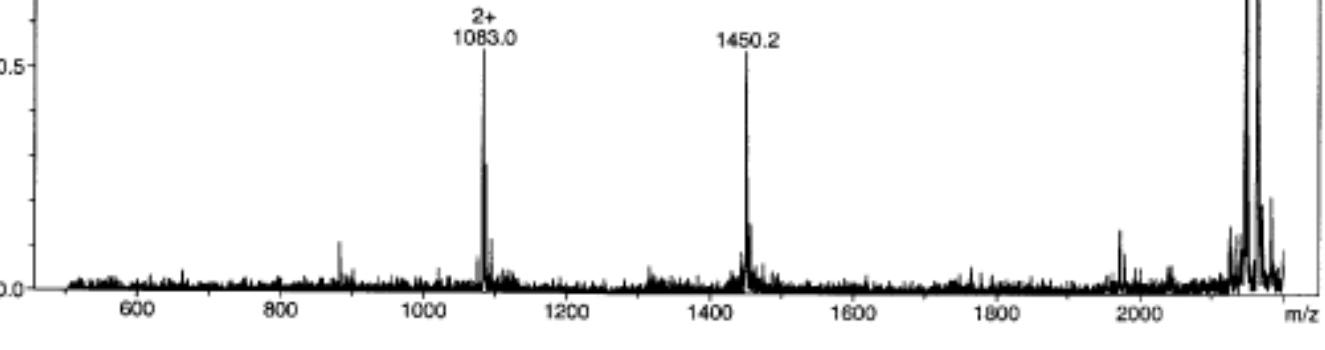

Bruker Daitonics DataAnalysis 3.0

printed: $\quad 02 / 03 / 04$

16:10:04

Page 1 of 1 


\section{Empower}

Result Set Report

Reported by User: labo

Project Name: Peptides

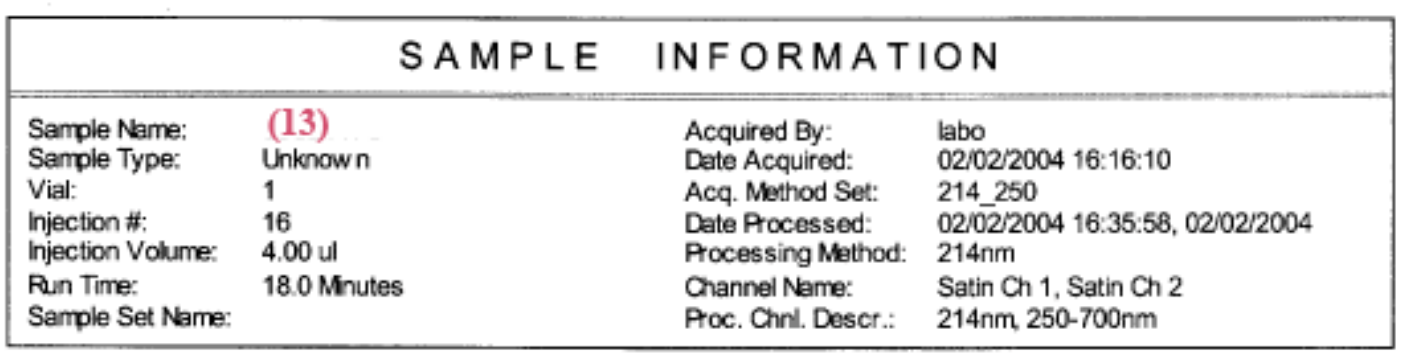
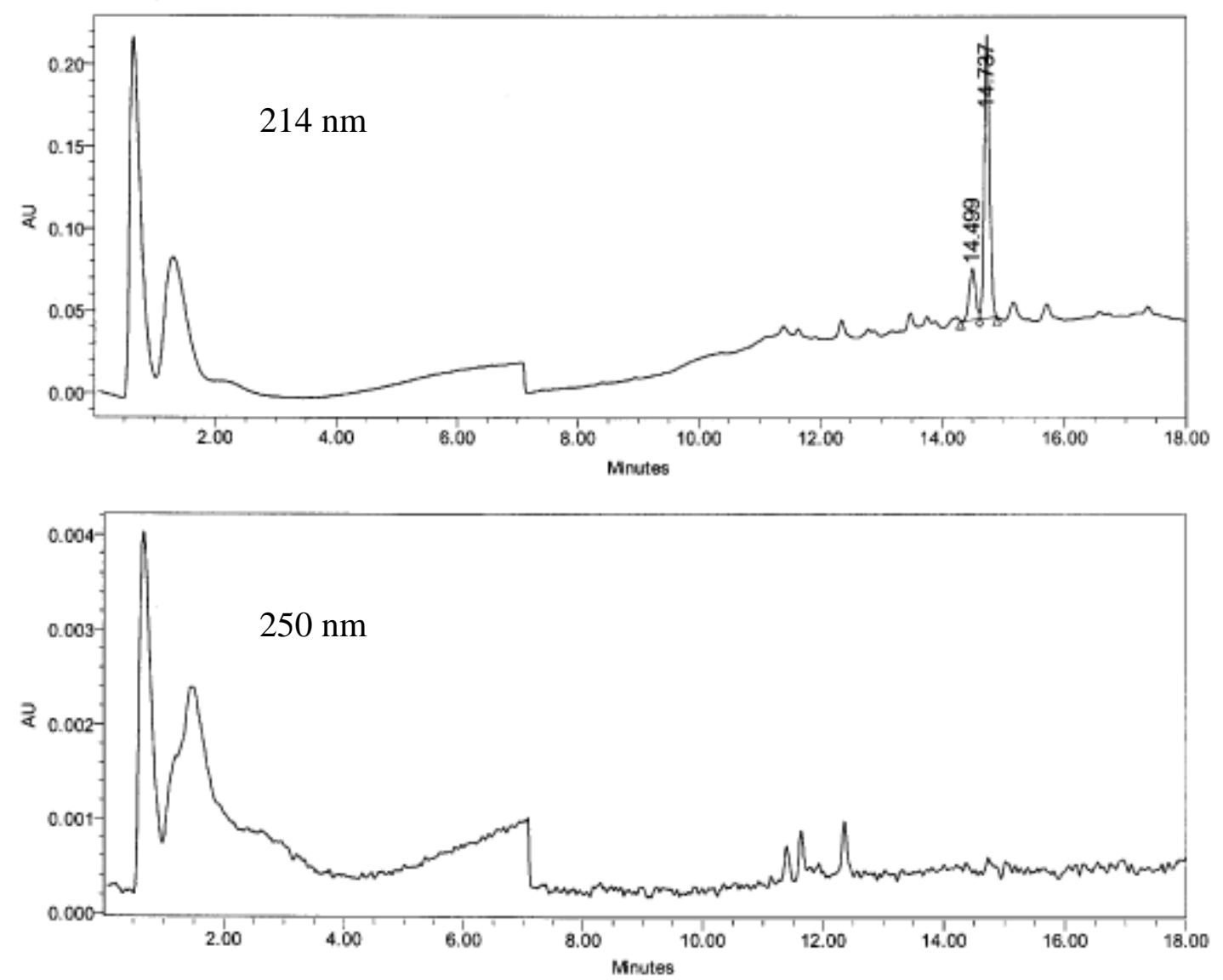

\begin{tabular}{|c|c|c|r|r|}
\hline & RT & Area & $\%$ Area & Height \\
\hline 1 & 14.499 & 223356 & 17.88 & 31414 \\
\hline
\end{tabular}$\quad$\begin{tabular}{|c|c|c|c|c|}
\hline & RT & Area & $\%$ Area & Height \\
\hline 2 & 14.737 & 1026048 & 82.12 & 171434 \\
\hline
\end{tabular}

Report Method: Result Set Report

Pinted 16:36:40

$02 / 02 / 2004$

Page: 2 of 3 


\section{Display Report}

Analysis Info Analysis Name

Method

Sample Name

Comment
(13)

Copy of peptide2.MS

Boturyn Didier

ret $\mathrm{O} 3 \mathrm{CO} 117 \mathrm{C}$

$200 \mathrm{ug} / 1 \mathrm{~mL}$ CH3CN puis $1 / 100$
Acquisition Date 02/03/04 16:16:27

Operator Default

Instrument esquire3000plus_01067

Acquisition Parameter

Icn Source Type ES

lcn source Type

ESI

Sid/Normal

$311 \mu \mathrm{s}$

Ion Polarity

Scan Begin

Shim 1

Positive

$500 \mathrm{~m} / \mathrm{z}$

40.0 Volt

Altemating lon Polarity

Scan End

Trap Drive

Aulo MS/MS

$2000 m / 2$

20 Spoctra

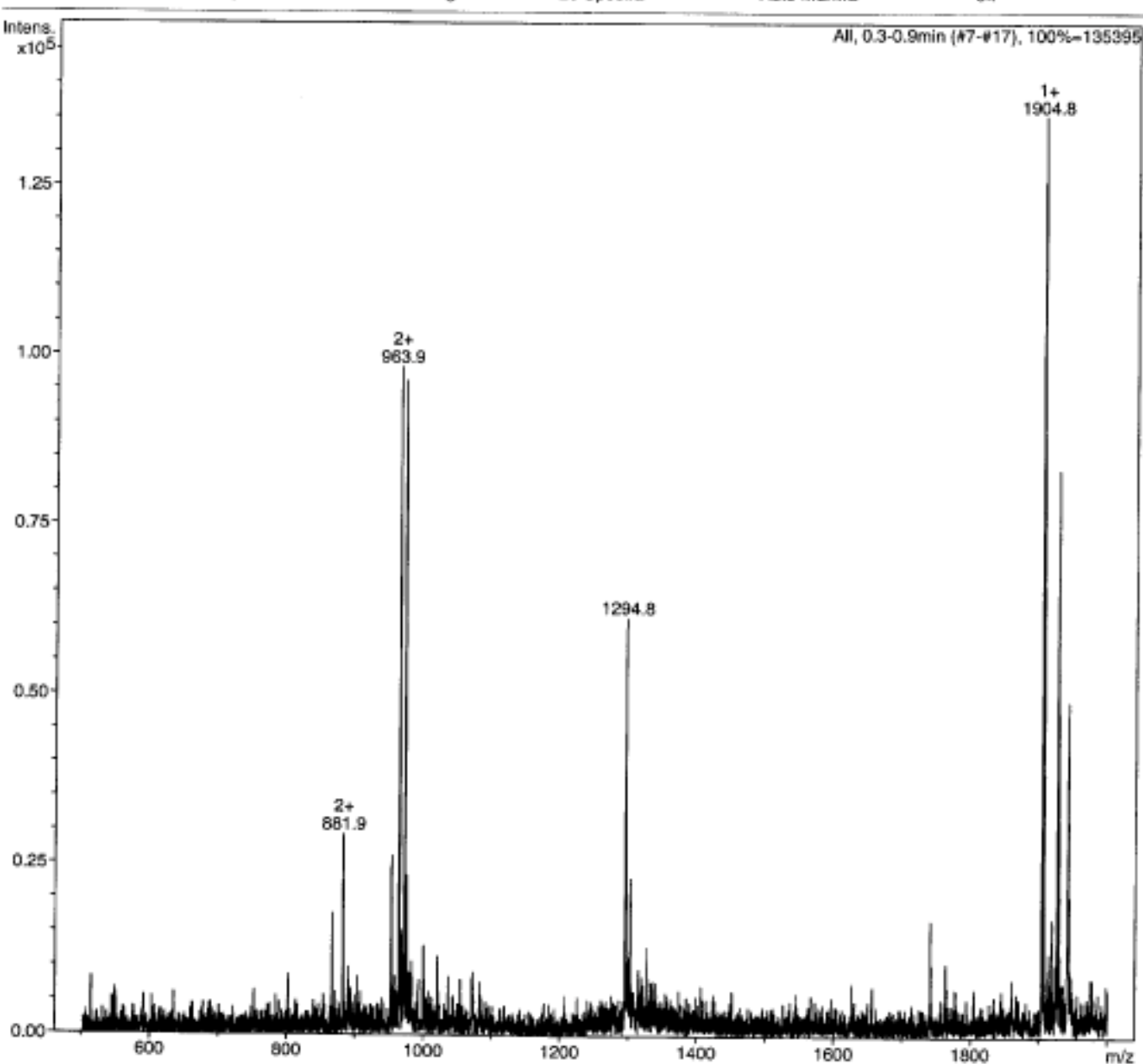

600

800 


\section{Ellipsometric measurements}

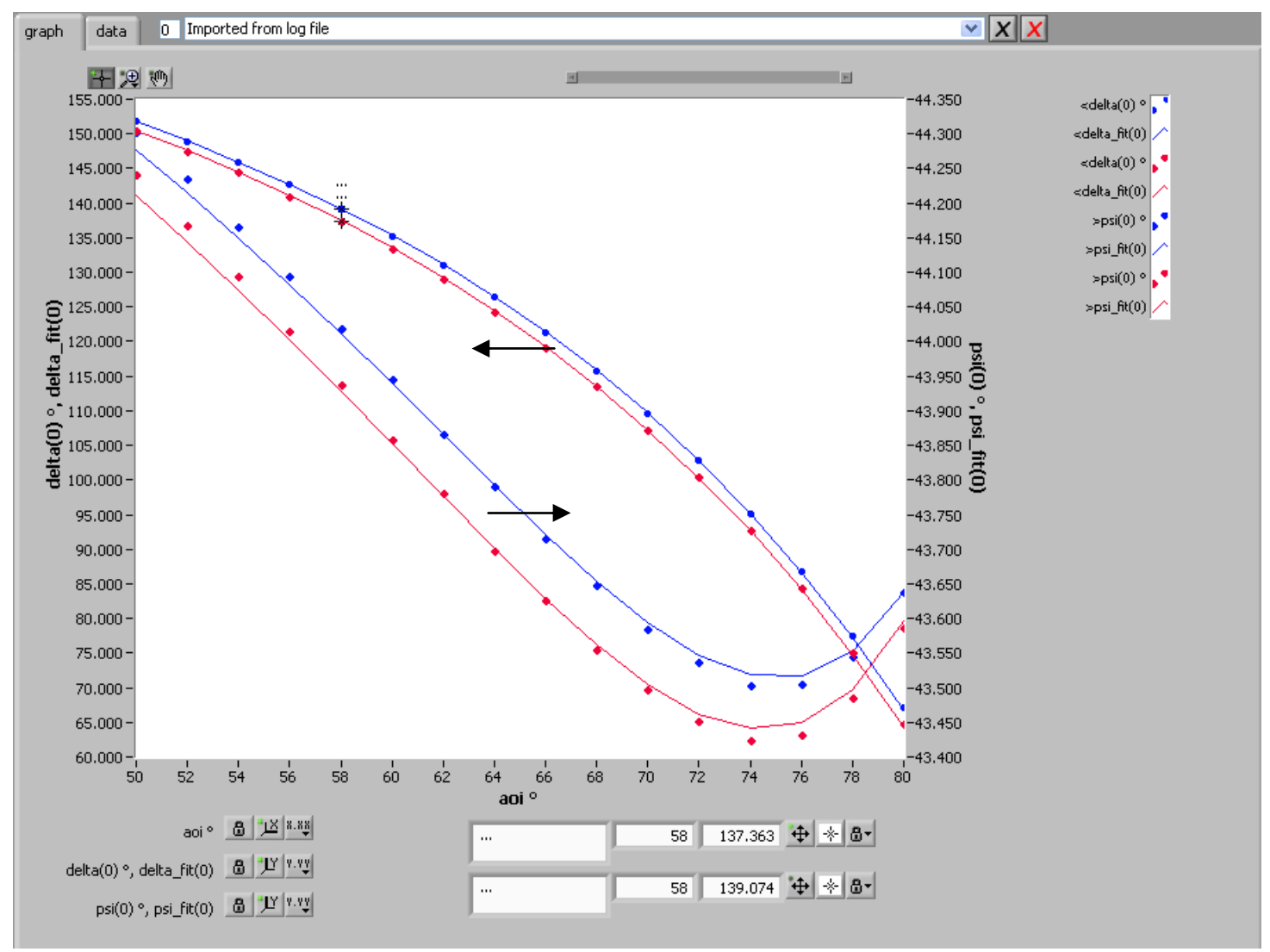

Experimental $\Delta$ and $\psi$ values (points) and best fits (line) as a function of incidence angle measured on the bare gold substrate (blue) and compound 2 modified substrate (red). The optical properties of substrate were fitted using a two-phase model (substrate/ambient air) and gave the following values: $\mathrm{n}_{\mathrm{s}}=0.197 \pm 0.011 ; \mathrm{k}_{\mathrm{s}}=3.537 \pm 0.011$ (mse $=1.26$ ). These values were used to fit the data of compound 2 modified substrate using a three-phase model (substrate/layer 2/ambient air). Using a fixed value $n=1.45$, the following values for the optical properties of the layer of 2 were obtained: $k=0.080 \pm 0.16$; $d=2.31 \pm 0.16 \mathrm{~nm}$ (mse $=1.15)$. 